\title{
The effects of supplementing diets with Atractylodes macrocephala Koidz rhizomes on growth performance and immune function in piglets*
}

\author{
C.L. Xu ${ }^{1,3}$, Y.F. Zhao ${ }^{2}$, X.Y. Shang ${ }^{1}$ and W.N. Niu ${ }^{1}$ \\ ${ }^{1}$ Laboratory of Chemical Biology \& Medicinal Chemistry, Faculty of Life Science, \\ Northwestern Polytechnical University \\ No. 127 Youyi West Road, Xi'an 710072, P.R. China \\ ${ }^{2}$ Department of Agriculture and Medicine, China Central Radio and TV University \\ No.160 Fuxingmennei Street, Beijing 100031, P.R. China
}

(Received 10 July 2011; revised version 10 February 2012; accepted 18 June 2012)

\begin{abstract}
The rhizome of Atractylodes macrocephala Koidz (baizhu in Chinese, AMK) is a well-known traditional Chinese medicine that has long been used as a digestive and tonic. The experiment was conducted to investigate the effect of baizhu powder on the growth performance and immune function of piglets. Duroc $\times$ Landrace $\times$ Yorkshire piglets $(n=72$, half males and half females, 42 days of age, liveweight $14.82 \pm 0.17 \mathrm{~kg}$ ) were randomly allocated to three treatments: control, control+AMK either ground $(\mathrm{GMD}=180 \mu \mathrm{m})$, or micronized $(\mathrm{GMD}=5.59 \mu \mathrm{m})$, for 30 days. The results showed that supplementation with micronized baizhu significantly increased average daily gain $(\mathrm{ADG})(\mathrm{P}<0.05)$ and decreased $(\mathrm{P}<0.05)$ the feed/gain and diarrhoea ratios compared with the control group. Pigs given 80 mesh baizhu had a lower $(\mathrm{P}<0.05)$ diarrhoea ratio than those fed the control diet. Supplementation with 80 mesh baizhu and micronized baizhu significantly increased $(\mathrm{P}<0.05)$ both concanavalin- $(\mathrm{ConA})$ and lipopolysaccharide (LPS)-induced splenocyte and peripheral lymphocyte proliferation, serum IgG, IL-1, and IL-2 concentrations $(\mathrm{P}<0.05)$ compared with the control group. In addition, supplementation with micronized baizhu significantly enhanced $(\mathrm{P}<0.05)$ PR-39 mRNA expression compared with the control group. The results indicate that baizhu could ameliorate metabolic status and regulate immune function to improve the growth performance of piglets, and that super-fine comminution may improve its medicinal efficiency.
\end{abstract}

KEY WORDS: Atractylodes macrocephala Koidz, growth performance, immunity, piglets

\footnotetext{
* Supported by the National Natural Science Foundation of China, Grant No. 31001012 and 31101304 , Northwestern Polytechnical University Foundation Science Research Fund, Grant No. JC201278 and JC201020

${ }^{3}$ Corresponding author: e-mail: clxu@nwpu.edu.cn
} 


\section{INTRODUCTION}

Antibiotics are frequently used on commercial pig farms not only to fight disease, but also to help pigs gain weight faster. Extensive use of antibiotics results, however, in residual medicaments in animal products, bacterial antibiotic resistance and tolerance (Lien et al., 2007). This represents a considerable risk to human health. Therefore, it has become urgent to develop a non-antibiotic immunopotentiator with high efficiency, low toxicity, and extensive resources. Many Chinese herbal medicines (CHM) have been reported to have immunopotentiation effects (Lien et al., 2007; Liu et al., 2010) and have great potential for practical application. Baizhu (the rhizomes of Atractylodes macrocephala Koidz, a member of the Compositae family) can invigorate the spleen, and cure patients with splenic asthenia, anorexia, oedema, excessive perspiration, and abnormal foetal movement. Atractylodes macrocephala Koidz (AMK) is used widely as a digestive and tonic ingredient in traditional oriental medicines (Yim et al., 1988). Recent investigations have suggested its potential ability to stimulate immune responses, although a scientific basis for this activity has not been elucidated yet. Oral administration of AMK markedly enhanced antigen-specific immune responses (Kim et al., 2002a,b). Dietary supplementation with AMK polysaccharide improved the immune response by elevating the proliferation of Lactobacillus, mRNA expression and level of cytokines, and ameliorating the proliferation of lymphocytes and metabolic status in early-weaned pigs (Li et al., 2011). Atractylenolide I and acetylenic compound from AMK were found to be active compounds in different anti-inflammatory assays ( $\mathrm{Li}$ et al., 2007). Glycoproteins from AMK markedly stimulated lymphocyte proliferation, antibody production, and cytokine secretion in mouse splenocytes (Lee et al., 2007). Those results indicated that the medicinal efficiency of AMK is related to its effective ingredient. In our previous research we found that Astragalus membranaceus prepared with different comminution techniques has significantly different effects on immune function and growth performance in young growing pigs, which may be related to the bioavailability of the effective ingredients (Hu et al., 2006).

Up to now, no studies have been done on the effect of AMK powder prepared by using different comminution techniques on growth performance and immune function of piglets. We hypothesized that supplementation of diets with AMK $(\mathrm{GMD}=180 \mu \mathrm{m}$ or $5.59 \mu \mathrm{m}, 1 \mathrm{~g} / \mathrm{kg}$ diet) may stimulate the immune system and nutritional metabolic processes and, therefore, improve growth performance in piglets. This hypothesis was tested by determination of growth performance and serum and tissue immune-status-related parameters in piglets. 


\section{MATERIAL AND METHODS}

\section{Chinese herbal medicine}

AMK (baizhu) was purchased from Huadong Pharmaceutical Company (Hangzhou city, China), washed with water, then dried at $40^{\circ} \mathrm{C}$ and processed in our lab to an ultramicro-powder using a QYF fluidized-bed pneumatic jet mill (Kunshan Miyou Industrial Co., Ltd. Kunshan, China) or to a conventional fine powder by using an SFY-K-2-type conventional mill (Kunshan Miyou Industrial Co., Ltd. Kunshan, China), respectively. The conventional fine powder was ground through an 80 mesh sieve. Particle sizes were determined by a Mastersizer Laser Particle Size Analyzer (Malvern, UK). The average particle size of 80 mesh baizhu and micronized baizhu used in the current study was 180 and $5.59 \mu \mathrm{m}$, respectively.

\section{Animals and experimental design}

This experiment was approved by the Institutional Animal Care and Use Committee at Zhejiang University and was conducted in accordance with the National Institutes of Health guidelines for the care and use of experimental animals. The feeding trial was carried out in the Swine Research and Teaching Farm at Zhejiang University. Duroc $\times$ Landrace $\times$ Yorkshire pigs $(n=72$; half males, half females), 42 days of age and weighing $14.82 \pm 0.17 \mathrm{~kg}$, were housed in an open-front pig barn with $350 \times 350 \mathrm{~cm}$ concrete floor pens. The pigs had been weaned on day 35 . The animals were randomly assigned to three treatments: 1 . control; 2. control +80 mesh baizhu $(\mathrm{GMD}=180 \mu \mathrm{m}, 1 \mathrm{~g} / \mathrm{kg}$ diet $) ; 3$. control +80 mesh baizhu (GMD=5.59 $\mu \mathrm{m}, 1 \mathrm{~g} / \mathrm{kg}$ diet). Each treatment had three replicates with eight pigs per pen. The diets were formulated to meet or exceed NRC (1998) requirements for piglets (Table 1). No antibiotic was included in diets.

The feeding trial lasted for 30 days after a seven-day adaptation period. During the 30-day feeding trial, all pigs were given ad libitum access to feed and water. Average daily gain (ADG), average daily feed intake (ADFI), feed/ gain and diarrhoea ratios [(number of pigs with diarrhoea per day $\times$ days of occurring diarrhoea)/(total experimental number of pigs $\times$ experimental days)] were calculated.

\section{Sample collection and assay}

Sampling procedure. After the feeding trial, six pigs from each treatment (two pigs per pen) were slaughtered under general anaesthesia. The pigs were fasted for $12 \mathrm{~h}$ and after intramuscular injection of sodium pentobarbital 
Table 1. Composition of experimental diets, as-fed basis

\begin{tabular}{lrlr}
\hline Ingredients, $\mathrm{g} / \mathrm{kg}$ & \multicolumn{3}{c}{ Analysed content, $\mathrm{g} / \mathrm{kg}$} \\
\hline Maize & 589 & Dry matter & 889 \\
Soyabean meal & 250 & Crude protein & 194 \\
Wheat midding & 50 & Calcium & 8 \\
Yeast & 10 & Total P & 6.6 \\
Fish meal & 40 & Lysine & 13.5 \\
Limestone & 8 & Methionine & 3.3 \\
Monocalcium phosphate & 20 & & \\
Sodium chloride & 3 & & \\
Vitamin-mineral premix $^{1}$ & 30 & & \\
DE $^{2}, \mathrm{MJ} / \mathrm{kg}$ & 14.46 & & \\
\hline
\end{tabular}

1 provided the following amounts of minerals/vitamins per kg of feed in experiment diets: IU: vit. A 2200, vit. $\mathrm{D}_{3}$ 500; mg: Fe 100, Cu 6, Mn 4, Zn 100, I 0.14, Se 0.3, vit. E 16, vit. K 0.5, vit. B 1.5 , vit. $\mathrm{B}_{2} 4$, vit. $\mathrm{B}_{6} 2$, vit. $\mathrm{B}_{12} 0.02$, niacin 22 , D-pantothenic acid 12 , biotin 0.08 , folic acid 0.3 , $2 \mathrm{DE}$ based on calculated values

solution, euthanized by bleeding. For primary cell culture, spleen samples were immediately obtained. Blood samples $(15 \mathrm{ml}$ per pig) were drawn in collection tubes by venipuncture of the anterior vena cava of pigs after 12-h fasting. Five $\mathrm{ml}$ of each blood sample were transferred immediately into aseptic capped tubes with sodium heparin and the remaining $10 \mathrm{ml}$ were allowed to clot at $37^{\circ} \mathrm{C}$ for $2 \mathrm{~h}$ prior to collecting serum.

Proliferation assay of splenocytes and peripheral lymphocytes. Spleens were cut into several pieces and gently crushed. Clumps were further dispersed by passing the suspension through a 19-G needle. Subsequently, the cell suspension was filtered through a $200-\mu \mathrm{m}$ stainless steel sieve, and cells were collected by centrifugation. The splenocytes were washed twice and then resuspended in RPMI 1640 (GIBCO BRL, USA) supplemented with benzyl-penicillin $(100 \mathrm{IU} / \mathrm{ml})$, streptomycin $(100 \mathrm{IU} / \mathrm{ml})$, and $10 \%$ foetal bovine serum (FBS). Blood samples with sodium heparin were diluted with an equal volume of Hanks' solution and carefully layered on the surface of lymphocyte separation medium. The lymphocyte band was collected and washed twice with RPMI 1640 without FBS. The splenocytes and peripheral lymphocytes were adjusted to $2 \times 10^{6} / \mathrm{ml}$ and $6 \times 10^{6} / \mathrm{ml}$, respectively, with RPMI 1640 media and incubated in 96-well tissue culture plates with $100 \mu \mathrm{l} /$ well, adding either $100 \mu \mathrm{l}$ of ConA ( $25 \mu \mathrm{g} / \mathrm{ml}$, SIGMA, USA), LPS (100 $\mu \mathrm{g} / \mathrm{ml}$, SIGMA, USA), or complete medium (controls). After $44 \mathrm{~h}$ of incubation at $37^{\circ} \mathrm{C}$ in a $5 \% \mathrm{CO}_{2}$ humid incubator, mitogeninduced splenocyte and peripheral lymphocyte proliferation was examined by 3-(4,5-dimethylthiazol-2-yl)-2,5-diphenyltetrazolium bromide (MTT) assay (Zhou et al., 2005). Twenty microlitres of MTT ( $5 \mathrm{mg} / \mathrm{ml}$, Amresco, Solon, USA) were added into each well and incubated for another $4 \mathrm{~h}$ and then $100 \mu \mathrm{l}$ of DMSO was added into each well and shaken for $10 \mathrm{~min}$ to dissolve the precipitation 
completely. The light absorbance was measured at $570 \mathrm{~nm}$ with an enzymelinked immunosorbent assay (ELISA) reader (Model BIO-RAD-550, USA). The stimulation index (SI) was calculated as the absorbance of mitogen-stimulated cells divided by the absorbance of unstimulated, control (media only) cells.

Serum IL-1, IL-2, IgA, and IgG assays. Concentrations of IL-1 and IL-2 in the serum were determined using commercial ELISA kits (Pharmingen, CA, USA) according to the manufacturer's instructions. The concentrations of serum $\operatorname{IgG}$ and IgA were measured by agar gel simple diffusion in two dimensions (Yang and Zheng, 1992).

Gene expression of antimicrobial peptide PR-39. The relative quantification of all gene transcripts was carried out by real-time quantitative PCR (RTPCR). Total RNA was isolated from bone marrow using Absolutely RNA ${ }^{\circledR}$ Microprep Kits (Stratagene, La Jolla, CA, USA) following the manufacturer's protocol. The RNA concentration of the samples was determined with an ND1000 spectrophotometer (Nanodrop Technologies, Wilmington, DE, USA). Purified RNA was transcribed into cDNA immediately using the High-Capacity cDNA Archive Kit (Applied Biosystems, Foster City, CA, USA), following the manufacturer's instructions. Real-time PCR (RT-PCR) was performed in a 7300 Real-Time PCR System (Applied Biosystems) using a SRBR ${ }^{\circledR}$ Green Mix (Applied Biosystems), total volume, $25 \mu$. When the reaction was completed, melting curves were plotted to confirm the product purity. For the PR-39 gene, a pair of oligonucleotide primers was designed by Primer Premier 5.0 software (PR-39, sense 5'-CGAGTCCCATCTCCCCACTT-3' and antisense 5'-CACCGTGAAGCTCACAGGTTT-3'; $\beta$-actin, sense 5'-CGGGACCTGACCG ACTACCT-3' and antisense 5'-GGCCGTGATCTCCTTCTGC-3'), based on the sequences registered in the GenBank database (GenBank/EMBL/DDBJ access number: PR-39, L23825; $\beta$-actin, BC067141). The relative abundance of gene transcripts was determined using a $2^{-\triangle \Delta \mathrm{Ct}}$ method with $\beta$-actin as the endogenous reference gene.

\section{Statistical analysis}

All data measured in the study were analysed by comparing means according to the least significant difference test, using the general linear model procedure of SAS (version 6.12). Pens were considered the experimental unit for growth performance analysis, the individual pig served as the experimental unit for other data analysis. Effects were considered significant at $\mathrm{P}<0.05$. 


\section{RESULTS}

\section{Effects of baizhu on growth performance}

Supplementation with micronized baizhu (Table 2) significantly increased ADG by $20.59 \%(\mathrm{P}<0.05)$, decreased the feed/gain ratio by $12.92 \%(\mathrm{P}<0.05)$, and decreased the diarrhoea ratio by $52.48 \%(\mathrm{P}<0.05)$ compared with the control group. Meanwhile, supplementation with 80 mesh baizhu decreased the diarrhoea ratio by $34.95 \%(\mathrm{P}<0.05)$ compared with the control group. Supplementation with 80 mesh baizhu had no effect $(\mathrm{P}>0.05)$, however, on growth performance compared with the control group. ADFI was not affected by diet.

Table 2. Effect of baizhu on growth performance and diarrhoea ratio of piglets ${ }^{1}$

\begin{tabular}{lccccc}
\hline \multirow{2}{*}{ Parameter } & \multirow{2}{*}{ Control } & \multicolumn{2}{c}{ Baizhu } & \multirow{2}{*}{ SEM } & \multirow{2}{*}{$\mathrm{P}$} \\
\cline { 3 - 4 } & & 80 mesh & micron & & \\
\hline Initial weight, $\mathrm{kg}$ & 14.80 & 14.79 & 14.87 & 0.535 & 0.937 \\
Final weight, kg & $38.59^{\mathrm{b}}$ & $39.89^{\mathrm{b}}$ & $43.56^{\mathrm{a}}$ & 0.816 & 0.012 \\
Average daily gain, g & $793.0^{\mathrm{b}}$ & $836.7^{\mathrm{b}}$ & $956.3^{\mathrm{a}}$ & 19.88 & 0.006 \\
Average daily feed intake, $\mathrm{kg}$ & 1.41 & 1.44 & 1.48 & 0.037 & 0.340 \\
Feed/gain & $1.78^{\mathrm{a}}$ & $1.72^{\mathrm{a}}$ & $1.55^{\mathrm{b}}$ & 0.031 & 0.037 \\
Diarrhoea ratio, \% & $9.47^{\mathrm{a}}$ & $6.16^{\mathrm{b}}$ & $4.50^{\mathrm{b}}$ & 0.586 & 0.027 \\
\hline I & means within a row with different letters $(\mathrm{a}, \mathrm{b})$ differ significantly (P<0.05). Values represent the \\
means of three replication (pens) per treatment. Treatments lasted 30 days &
\end{tabular}

\section{Effects of baizhu on splenocyte and lymphocyte proliferation}

Supplementation with micronized baizhu (Table 3) significantly increased $(\mathrm{P}<0.05)$ both ConA and LPS-induced splenocyte and lymphocyte proliferation significantly increased $(\mathrm{P}<0.05)$ both $\mathrm{ConA}$ and LPS-induced peripheral when compared with the control group. Supplementation with 80 mesh baizhu

Table 3. Effect of baizhu on splenocyte and lymphocyte proliferation ${ }^{1}$

\begin{tabular}{|c|c|c|c|c|}
\hline \multirow{3}{*}{ Group } & \multicolumn{2}{|c|}{ Peripheral lymphocyte proliferation } & \multicolumn{2}{|c|}{ Splenocyte proliferation } \\
\hline & ConA $^{2}$ & $\mathrm{LPS}^{3}$ & $\operatorname{Con}^{2}$ & $\mathrm{LPS}^{3}$ \\
\hline & \multicolumn{4}{|c|}{ induced (SI) } \\
\hline Control & $1.62^{\mathrm{c}}$ & $1.38^{\mathrm{b}}$ & $1.78^{\mathrm{c}}$ & $1.65^{\mathrm{b}}$ \\
\hline 80 mesh baizhu & $2.24^{\mathrm{b}}$ & $1.89^{\mathrm{a}}$ & $2.19^{\mathrm{b}}$ & $1.85^{\mathrm{b}}$ \\
\hline Micron baizhu & $2.79^{\mathrm{a}}$ & $2.07^{\mathrm{a}}$ & $2.73^{\mathrm{a}}$ & $2.39^{\mathrm{a}}$ \\
\hline SEM & 0.043 & 0.038 & 0.032 & 0.057 \\
\hline P-value & 0.000 & 0.008 & 0.003 & 0.014 \\
\hline
\end{tabular}


significantly increased $(\mathrm{P}<0.05)$ both $\mathrm{ConA}$ and LPS-induced peripherial lymphocyte proliferation and ConA-induced splenocyte proliferation compared with the control.

Effects of baizhu on IL-1, IL-2, IgA, and $\operatorname{Ig} G$

Pigs fed with micronized baizhu had higher $(\mathrm{P}<0.05)$ IgG, IgA, IL-1, and IL-2 serum concentrations than those fed other diets. In addition, supplementation with 80 mesh baizhu significantly increased $(\mathrm{P}<0.05)$ serum IgG, IL-1 and IL-2 concentrations compared with the control group (Table 4).

Table 4. Effect of baizhu on immune indexes in serum of piglets ${ }^{1}$

\begin{tabular}{|c|c|c|c|c|c|}
\hline \multirow{2}{*}{$\begin{array}{l}\text { Immune } \\
\text { indexes }\end{array}$} & \multirow{2}{*}{ Control } & \multicolumn{2}{|c|}{ Baizhu } & \multirow{2}{*}{ SEM } & \multirow{2}{*}{$\mathrm{P}$} \\
\hline & & 80 mesh & micron & & \\
\hline$\overline{\mathrm{IgG}, \mathrm{g} / \mathrm{l}}$ & $4.25^{\mathrm{b}}$ & $5.23^{\mathrm{a}}$ & $5.75^{\mathrm{a}}$ & 0.151 & 0.035 \\
\hline IgA, g/1 & $0.32^{\mathrm{b}}$ & $0.45^{\mathrm{a}}$ & $0.47^{\mathrm{a}}$ & 0.022 & 0.007 \\
\hline IL-1, pg/ml & $2.06^{\mathrm{c}}$ & $2.42^{\mathrm{b}}$ & $2.79^{\mathrm{a}}$ & 0.065 & 0.017 \\
\hline IL-2, pg/ml & $15.13^{\mathrm{c}}$ & $19.16^{\mathrm{b}}$ & $23.24^{\mathrm{a}}$ & 0.713 & 0.000 \\
\hline
\end{tabular}

Effect of baizhu on PR-39 mRNA expression

Supplementation with micronized baizhu significantly increased the PR-39 relative mRNA expression level by $152.13 \%(\mathrm{P}<0.05)$ compared with the control group (Figure 1), whereas supplementation with 80 mesh baizhu had no $(\mathrm{P}>0.05)$ effect.

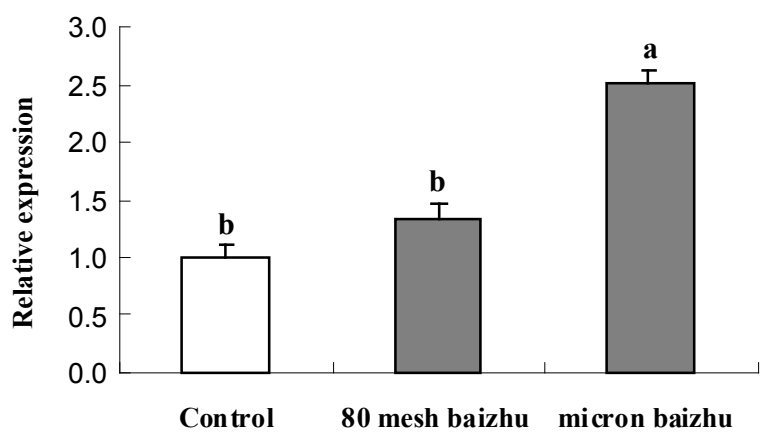

Figure 1. Changes $( \pm$ SEM) in the relative expression of antimicrobial peptide PR-39 gene in pig bone marrow in different treatments. $\beta$-actin was used as endogenous reference gene; $a$ and $b$ on error bar indicated values differed $(\mathrm{P}<0.05)$ 


\section{DISCUSSION}

Li (2002) and others reported that supplementation with 2\% Chinese herbal medicines (CHM) (including huangqi, dang-shen, baizhu, fu-ling, etc.) can significantly decrease the diarrhoea ratio. In the current study, the growth performance results showed that supplementation with micronized baizhu significantly increased ADG and decreased the feed/gain ratio of piglets, whereas supplementation with 80 mesh baizhu had no effect on growth performance. Moreover, pigs fed with micronized or 80 mesh baizhu had a lower diarrhoea ratio. The feeding value of baizhu may be affected by the concentration at which it is added, preparation techniques, sanitary conditions, diet composition, and so on. The current results suggest that baizhu did improve growth performance and that this effect depended on the preparation technique. In our previous research we found that micronized Astragalus significantly increased the ADG of young growing pigs (Hu et al., 2006).

Splenocyte and peripheral blood lymphocyte proliferation and serum IgA, IgG, IL-1 and IL-2 levels reflect immune function. Some CHM significantly increased IL-1 activity and promoted IL-2 release (Wu et al., 2010; Zhao et al., 2011). IL-2 is a cytokine produced by activated T cells that has shown powerful immunostimulatory and antineoplastic properties (Lee et al., 2005). Previous in vivo and in vitro results have shown that baizhu could promote ConA and LPSinduced splenocyte and peripheral lymphocyte proliferation (Lee et al., 2007). The underlying mechanisms are largely unknown, however. In the present study, we also found that supplementation with micronized baizhu significantly promoted ConA or LPS-induced spleen and peripheral lymphocyte proliferation, and significantly increased IL-1, IL-2, IgA and IgG levels, which indicates that micronized baizhu had an effective immune enhancing activity. Supplementation with 80 mesh baizhu had some effect on improving immune function, but it was smaller than that of micronized baizhu. These results suggest that the effect of baizhu on immune function depended on the comminution technique.

Antimicrobial peptides are an important first line of defense against microbial invasion and play a prominent role in host defense mechanisms of innate immunity (Brogden et al., 2003). PR-39, a proline-arginine-rich 39-amino-acid residue antimicrobial peptide, is synthesized by bone marrow progenitor cells (Zanetti et al., 1995). Wu et al. (1999) investigated the gene expression of porcine PR-39 during the first month of life. PR-39 was expressed constitutively in the bone marrow of all pigs at all of the ages tested. Peripheral blood neutrophils from young pigs expressed PR-39 mRNA, which was not detectable at 42 days of age. At earlier ages, expression of PR-39 mRNA was detected in the kidney and liver and several lymphoid organs, including the thymus, spleen and mesenteric 
lymph nodes, but disappeared at 4 weeks of age. Those data may indicate a role for the antimicrobial peptide in the development of host defense mechanisms. And the following experiment results showed that LPS, IL-6, and retinoic acid significantly up-regulated PR-39 gene expression (Wu et al., 2000). Micronized Astragalus and Astragalus polysaccharides significantly enhanced PR-39 gene mRNA expression (Tu et al., 2006). The results from the current experiment show that supplementation with micronized baizhu could significantly increase the gene expression of PR-39. Previous studies revealed that the 5' flanking region of the PR-39 gene contained several potential regulatory motifs, nuclear factor (NF)-kB, NF-IL-6, and IL-6 response elements (IL-6 RE) (Wu et al., 2000). Taken together, these findings suggest that extrinsic modulation of this innate host defense mechanism may be possible.

The principal finding of the current study is that micronized baizhu is more effective than 80 mesh baizhu in improving growth performance and immune function in piglets. Many researchers confirmed the efficacy of super-fine comminution CHM (Li et al., 2004; Xu et al., 2004). Possible mechanisms have been suggested: first, that preparation of CHM plant cell walls by super-fine comminution highly disrupts them, enabling free access of digestive enzymes to the released intracellular contents; second, that baizhu prepared by super-fine comminution has relatively fine particles and large surface area, which enhances adhesive properties and prolongs the time of settling and releasing of baizhu in the body. These mechanisms would also improve absorption rate and bioavailability.

It is believed that Atractylodes macrocephala Koidz (AMK) might play a pivotal role in traditional oriental medicines with immune modulation function. The present study focused on investigating whether AMK exhibits immune-stimulating activity and on elucidating the identity of the major ingredients responsible for this activity. The immunological effect and the effective mechanisms of baizhu on piglets are still unclear, however. It has been reported that the immune stimulatory effects of many oriental medicinal herbs are associated with their main active components such as polysaccharides, glycoproteins, etc. (Yoshida et al., 1997). The rhizomes of Atractylodes macrocephala Koidz are rich in sesquiterpenes, acetylenic, polysaccharides, and glycoproteins (Lee et al., 2007; Li et al., 2011). Glycoproteins in the AMK sample were the most prominent ingredients responsible for splenocyte stimulation and cytokine secretion (Lee et al., 2007). The polysaccharide fractions of AMK have been reported to improve humoral immunity in pigs ( $\mathrm{Li}$ et al., 2007). Low molecular weight substances, including sesquiterpenoids and triterpenoids, were identified from AMK as inhibitors of $\mathrm{Na}^{+}-$ $\mathrm{K}^{+}$-ATPase and neuromuscular connections (Kimura et al., 1995). The activity of the major ingredients and the mechanisms of their immunomodulatory activity should be investigated further. 


\section{CONCLUSIONS}

Our findings suggest that micronized baizhu was more effective than 80 mesh baizhu in improving growth performance and immune function in pigs. The comminution technique may affect the medicinal efficiency of baizhu in practice. Further research needs to be conducted to better understand the effect and mode of action of baizhu of various particle sizes. If further studies confirm its immunostimulatory effects, this potential may promote the development of a novel immunopotentiator that may be used in the pig industry.

\section{REFERENCES}

Brogden K.A., Ackermann M., McCray Jr P.B., Tack B.F., 2003. Antimicrobial peptides in animals and their role in host defences. Int. J. Antimicrobial Agents 22, 465-478

Hu Y.L., Xu C.L., Wang Y.Z., Li Y.J., Liu J.X., Feng J., 2006. Effect of dried roots of Astragalus membranaceus in the diets of young growing pigs on growth performance and immune function. J. Anim. Feed Sci. 15, 599-607

Kim E.H., Lee J.C., Kim J., Son Y.O., Jung G.H., Jang Y.S., 2002a. Modulation of antigen-specific immune responses by the oral administration of a traditional medicine, Bo-yang-hwan-o-tang. Immunopharmacol. Immunotoxicol. 24, 423-440

Kim E.H., Lee J.C., Park C.H., Lee M.Y., Jang Y.S., 2002b. Soamsan, a traditional Korean medicine, enhances antigen-specific immune responses in low-responder mice via the combined activity of glycoproteins and endotoxins. Int. Immunopharmacol. 2, 1529-1540

Kimura M., Diwan P.V., Yanagi S., Kon-no Y., Nojima H., Kimura I., 1995. Potentiating effects of beta-eudesmolrelated cyclohexylidene derivatives on succinylcholine induced neuromuscular block in isolated phrenic nervediaphragm muscles of normal and alloxan-diabetic mice. Biol. Pharmacol. Bull. 18, 407-410

Lee Y.S., Han O.K., Park C.W., Yang C.H., Jeon T.W., Yoo W.K., Kim S.H., Kim H.J., 2005. Pro-inflammatory cytokine gene expression and nitric oxide regulation of aqueous extracted Astragali Radix in RAW 264.7 macrophage cells. J. Ethnopharmacol. 100, 289-294

Lee J.C., Lee K.Y., Son Y.O., Choi K.C., Kim J., Kim S.H., 2007. Stimulating effects on mouse splenocytes of glycoproteins from the herbal medicine Atractylodes macrocephala koidz. Phytomedicine 14, 390-395

Li C.M., Gai G.S., He X.H., Xing D.M., 2004. Application of powder technology in Chinese traditional medicine. China Powder Technol. 3, 48-51

Li C.Q., He L.C., Dong H.Y., Jin J.Q., 2007. Screening for the anti-inflammatory activity of fractions and compounds from Atractylodes macrocephala koidz. J. Ethnopharmacol. 114, 212-217

Li L.L., Yin F.G., Zhang B. et al., 2011. Dietary supplementation with Atraactylodes Macrophala Koidz polysaccharides ameliorate metabolic status and improve immune function in earlyweaned pigs. Livest. Sci. 142, 33-41

Lien T.F., Horng Y.M., Wu C.P., 2007. Feasibility of replacing antibiotic feed promoters with the Chinese traditional herbal medicine Bazhen in weaned piglets. Livest. Sci. 107, 97-102

Liu F.X., Sun S.H., Cui Z.Z., 2010. Analysis of immunological enhancement of immunosuppressed chickens by Chinese herbal extracts. J. Ethnopharmacol. 127, 251-256

NRC, 1998. Nutrient Requirements of Swine. 10 ${ }^{\text {th }}$ Edition. National Academy Press. Washington, DC 


\section{ATRACTYLODES MACROCEPHALA KOIDZ RHIZOMES FOR PIGLETS}

Tu Y.J., Xu C.L., Wang Y.Z., Yao G.J., Shan T.Z., 2006. Semiquantitative RT-PCR analysis to assess the effect of Astragalus and Astragalus polysaccharide on antimicrobial peptides PR-39 and protegrin gene expression in piglets. Turk. J. Vet. Anim. Sci. 30, 325-330

Wu C.R., Jiang X., He S.T., Yang B., Hu J.Z., Cai R., 2010. Effect of QWBZP on T-cell subsets and their cytokines in intestinal mucosa of HRV infection sucking mice. J. Ethnopharmacol. 131, $130-134$

Wu H., Zhang G.L., Minton J.E., Ross C.R., Blecha F., 2000. Regulation of cathelicidin gene expression: Induction by lipopolysaccharide, Interleukin-6, retinoic acid, and salmonella enterica serovar typhimurium infection. Infec. Immunity 68, 5552-5558

Wu H., Zhang G. L., Ross C. R., Blecha F., 1999. Cathelicidin gene expression in porcine tissues: Roles in ontogeny and tissue specificity. Infec. Immunity 67, 439-442

Xu L.J., Lu F.E., Zou X., Wei S.C., 2004. A study of the solubilization of Rhizoma Coptidis powdered to micrometer particles. Herald Med. 23, 374-375

Yang H.C., Zheng S.J., 1992. Experimental Techniques in Veterinary Immunology. Beijing Agricultural University Press, Beijing (China)

Yim D.S., Yu S.C., Chi H.J., 1988. Phytochemical study on the Rhizome of Atractylodes japonica from Korea (Korean). Korean J. Pharmacogn. 19, 228-232

Yoshida Y., Wang M.Q., Liu J.N., Shan B.N., Yamashita U., 1997. Immunomodulating activity of Chinese medicinal herbs and Oldenlandia diffusa in particular. Int. J. Immunopharmacol. 19, 359-370

Zanetti M., Gennaro R., Romeo D., 1995. Cathelicidins: a novel protein family with a common proregion and a variable C-terminal antimicrobial domain. FEBS Lett. 374, 1-5

Zhao N., Zhang W.D., Guo Y.M., Jia H.W., Zha Q.L., Liu Z.L., Xu S.J., Lu A.P., 2011. Effects on neuroendocrinoimmune network of Lizhong Pill in the reserpine induced rats with spleen deficiency in traditional Chinese medicine. J. Ethnopharmacol. 133, 454-459

Zhou J.Y., Wang J.Y., Chen J.G., Wu J.X., 2005. Cloning, in vitro expression and bioactivity of duck interleukin-2. Mol. Immunol. 42, 589-598

Zou Y.M., 2005. Comparative study on bulk density, liquidity the effective ingredient of the micro powder and fine powder of three traditional Chinese medicinal materials. Lishizhen Med. Mat. Medica Res. 16, 761-762 